\title{
Redesigning Medical Uniforms in a Junior Level Collaborative Studio
}

\author{
Injoo Kim and Brooke Brandewie \\ University of Cincinnati, USA
}

Key words: collaborative, medical uniform, sponsorship, problem-based learning

Introduction During the fall semester at the School of Design of the College of Design, Architecture, Art \& Planning (DAAP) at the University of Cincinnati, junior students from three design disciplines (Fashion, Graphic, and Industrial Design) choose from an array of industrysponsored (i.e. $\mathrm{P} \& \mathrm{G}$, Luxottica, Boeing) design projects to participate in as a designated collaborative studio course. These collaborative projects require students to apply, analyze and synthesize qualitative research data into realized design solutions. This is an integral aspect of the design curriculum at the School of Design at UC because problem-based learning (PBL) allows students a guided experience in solving complex, real-world problems (Hmelo-Silver, 2004). Since a driving force of design is what the consumer needs/wants, it is critical that we work with industry, and imperative that we simultaneously enhance students' learning and professional competence. This project describes a case study from the Fall 2014/15 semester that focused on redesigning the medical uniforms for the University of Cincinnati Medical Center (UCMC). It is an example of industry-sponsored (covering classroom expenses and student scholarships) interdisciplinary problem-based learning as a new pedagogical framework. Students enhanced the quality of their learning through generating innovative medical uniform concepts. This project also illustrates how industry-sponsored and interdisciplinary PBL is both innovative and challenging.

Thus the purpose of this Collaborative Studio was focused holistically on the intersection of effective problem-solving skills including in-depth analysis of the problem and empathetic attitudes towards the problem, as well as self-directed learning (SDL) skills and successful collaboration skills.

Class Activities Four faculty members in the Fashion Design Program and the College of Medicine at UC investigated the existing problems with the UCMC scrubs through interviews and surveys as the initial step. From this preliminary research and evaluation we then defined a project statement for the Collaborative Studio class. A budget was then submitted to UCMC to carry out the project. We recruited 20 students from multiple disciplines including nursing, business, and communications as well as fashion and industrial design. The 20 students were split into small groups of 3-4 each, based on their skill sets and strengths.

For this course, the students were given the task of designing a new medical uniform/scrub. They began the investigative phase, utilizing qualitative research methods to inquire and understand the problem(s). This included interviews with stakeholders such as surgeons, doctors, nurses and residents; additionally, they visited the medical staff within their environments i.e. the hospital and Operation Room. Subsequent to this research, the students began to develop visions and solutions to the project problem(s); with doctors/ "clients" as the audience, each group then presented their respective findings with 20 new designs for scrubs. Included in these new designs were modifications based on such variables as size, gender, fit, 
age and functionality. Critiques from medical staff, as well as class critiques, helped refine the final design. The next step was for them to create 3D muslin prototypes to understand proportion, scale and usability of their ideas. Three groups were chosen for financial awards as best design solutions, including synchronicity with the UCMC identity/brand. The students' prototypes were produced and will be showcased in the Annual DAAP Fashion Show in May 2015. Moving forward, some of their designs will be adopted by UCMC.

Learning Outcomes In this Collaborative Studio course, communication and teamwork were key components of the process to ensure that the students arrived at the most efficacious solutions. The emphasis on communication and teamwork was both internal and external - that is, within the class and groups as well as with the stakeholders (doctors/clients) seeking a design solution. As the students sought to meet specific users' needs, the pressure to satisfy such requirements provided a valuable real-world experience in which ownership of both the design problem and the design solution was a strong motivator. Thus, by seeking to solve for real-world complex issues in interdisciplinary teams, students went beyond simply learning the facts relative to the project; they came to understand empathy, which is a critical aspect of the design process. Through empathy, they learned how to achieve the best possible design solution that was both aesthetically and functionally successful. Many of the students are used to working within their disciplines on individual projects; interdisciplinary project opportunities allow students to learn about each other's skills and how to leverage them to achieve a successful outcome.

Conclusions There are numerous and obvious pedagogical benefits to industry-sponsored, interdisciplinary problem-based learning, even as there are challenges to achieving these benefits. Problem-Based Learning is effective in helping design students achieve key skills including critical thinking, problem solving, teamwork, written and verbal communication skills and self-directed, life-long learning skills (Hmelo-Silver, 2004). Collaborative studios offer students the opportunity to work with different design disciplines, clients, and categories that may be outside their area of expertise. Since critiques are an integral aspect of the process, complex coordination by the faculty must be done in advance to ensure students receive feedback from the necessary stakeholders. Medical professionals' priorities must first go to their patients and clinical responsibilities, so scheduling in advance can be difficult. Semesters are 15 weeks long, forcing students to conceptualize and quickly refine solutions. While it is enough time to develop design ideas, it is a challenge to produce fully vetted and realized solutions. It is beneficial at the onset to identify with the client/sponsor what the "deliverables" will be and how the concepts generated from the project will be further developed. In the end, the students in this Collaborative Studio Course moved past the frustrations of time constraints and the work demanded of solving a complex apparel design problem, to a sense of success in meeting the needs of their clients' expectations for an improved and innovative scrub design.

Hmelo-Silver, C. E. (2004). Problem-Based Learning: What and How Do Students Learn?. Educational Psychology Review, (Vol. 16.3), pp. 235. 